PONTIFÍCIA UNIVERSIDADE CATÓLICA DO RIO DE JANEIRO

Empreendedorismo Feminino:

Desafios, adaptaçoes e motivações no periodo de pandemia no Brasil, na cidade do Rio de Janeiro Beatriz de Oliveira

Trabalho de Conclusão de Curso

CENTRO de CIÊNCIAS SOCIAIS - CCS

DEPARTAMENTO DE ADMINISTRAÇÃo

Graduação em Administração de Empresas 
Beatriz de Oliveira

\section{Empreendedorismo Feminino:}

Desafios, adaptaçoes e motivações no periodo de pandemia no Brasil, na cidade do Rio de Janeiro

\section{Trabalho de Conclusão de Curso}

Trabalho de Conclusão de Curso, apresentado ao programa de graduação em Administração da PUC-Rio como requisito parcial para a obtenção do título de graduação em Administração.

Orientadora: Andrea Bittencourt 


\section{Resumo}

Oliveira, Beatriz. Empreendedorismo Feminino: desafios, adaptações e motivações no período de pandemia no Brasil, na cidade do Rio de Janeiro. Rio de Janeiro, 2021. 28 p. Trabalho de Conclusão de Curso Departamento de Administração. Pontifícia Universidade Católica do Rio de Janeiro.

Com o passar dos anos, o empreendedorismo feminino tem crescido e o aumento de mulheres que buscam empreender pode ser explicado por diversos fatores como: falta de oportunidade de trabalho no mercado tradicional, autonomia, realização profissional, flexibilidade, dentre outros fatores. Com o surgimento inesperado da pandemia do covid-19, muitos empreendedores tiveram que encerrar suas operações e em contrapartida, houve o surgimento de novas oportunidades de trabalho e negócios. O presente trabalho tem como objetivo entender quais foram os desafios, as adaptações e as motivações que mulheres empreendedoras da cidade do Rio de Janeiro tiveram nesse período de pandemia.

Palavras-chave: Empreendedorimo, Desafios, Motivações, Pandemia do Covid19.

\section{Abstract}

Oliveira, Beatriz. Female Entrepreneurship: challenges, adaptations and motivations in the pandemic period in Brazil, in the city of Rio de Janeiro. Rio de Janeiro, 2021. 28 p. Trabalho de Conclusão de Curso Departamento de Administração. Pontifícia Universidade Católica do Rio de Janeiro.

Over the years, female entrepreneurship has grown and the increase of women seeking to become entrepreneurs can be explained by several factors such as: lack of job opportunities in the traditional market, autonomy, professional fulfillment, flexibility, among other factors. With the unexpected outbreak of the covid-19 pandemic, many entrepreneurs had to shut down their operations and, on the other hand, new job and business opportunities emerged.This paper aims to understand what were the challenges, adaptations, and motivations that women entrepreneurs in the city of Rio de Janeiro had during this pandemic period.

Keywords: Entrepreneurship, Challenges, Motivations, Covid-19 Pandemic. 


\section{Sumário}

1. O tema e o problema de estudo 1

1.1. Introdução ao tema e ao problema do estudo 1

1.1.2 Pandemia Global 2

1.2. Objetivo do Estudo 3

1.3. Objetivos Específicos 4

1.4. Justificativa e relevância do estudo 4

2. Referencial Teórico 5

2.1 Empreendedorismo 5

2.1.2 Empreendedorismo no Brasil e no Rio de Janeiro 6

2.2. Empreededorismo Feminino 9

2.3 Motivação 11

2.3.1 Teorias da Motivação

2.4 Motivação no Empreendedorismo Feminino 16

3. Métodos e procedimentos de coleta e de análise de dados do estudo 17

3.1 Procedimentos e instrumentos de coleta de dados utilizados no estudo 18

3.2 Formas de tratamento e análise dos dados coletos para o estudo 18

$\begin{array}{ll}3.3 \text { Limitações do estudo } & 19\end{array}$

4. Apresentação e análise dos resultados $\quad 19$

4.1. Análise dos resultados 20

5. Conclusões e recomendações para novos estudos 28

5.1 Sugestões e recomendações para novos estudos 29

6. Referências Bibliográficas

Lista de figuras

Figura 1: Evolução das taxas em \% - 2002-2019 7

Figura 2: Taxa de empreendedorismo em \% 8

Figura 3: Perfil do empreendedor do Rio de Janeiro por gênero 10

Figura 4: Comparação da Teoria X e Teoria Y 12

Figura 5: Hierarquia das necessidades de Maslow 14

Figura 6: Fatores motivacionais X Higiênicos 15

Figura 7: faixa etária de empreendedores Total (homens e mulheres) - perfil 
Brasil $\quad 22$

Figura 8: Percentuais de empreendedorismo iniciais por gênero 29 Lista de Gráficos:

Gráfico 1: faixa etária $\quad 22$

Gráfico 2: Escolaridade das entrevistadas 23

Gráfico 3: oportunidade X necessidade 24

Gráfico 4: Teve algum motivo que te fez desistir do seu negócio ou querer desistir 25

Gráfico 5: motivações utilizando opções retirada da pesquisa GEM Brasil 25

Gráfico 6: motivações 26

Gráfico 7: porcentagens do impacto da pandemia no negócio 27

Gráfico 8: ferramentas digitais 28

Anexos:

Anexo 1: Estrutura do Questionário : 


\section{O tema e o problema de estudo}

O primeiro capítulo deste trabalho apresenta o tema proposto do estudo, o problema de pesquisa, assim como o objetivo, a delimitação e a relevância do trabalho.

\subsection{Introdução ao tema e ao problema do estudo}

Este artigo discorre sobre o tema empreendedorismo feminino, tendo como foco conhecer os desafios, as adaptações e as motivações enfrentadas pelas mulheres da cidade do Rio de Janeiro nesse período de pandemia.

Sobre o tema empreendedorismo, também está relacionada a inovação e a criatividade, o que abre espaço para o conceito do intraempreendedorismo, pois não necessariamente pode esta ligada a criação de um negócio. (JULIANO, 2011).

Há alguns anos esse tema vem ganhando a atenção de políticos, economistas e acadêmicos pela participação e contribuição no crescimento da economia e desenvolvimento da sociedade em todo o mundo.

A participação de mulhereres na criação de empresas no mundo vem crescendo, a cada ano, de 18\% em 2016 para 25\% em 2019 de acordo com o estudo Wowem in the boardroom: Uma Perspectiva Global realizado pela Deloitte, um número muito inferior à participação masculina, mas com grande relevância economica, produtiva e social para os países.

A pesquisa "A diversidade como alavanca de performance" feita pela consultoria McKinsey (2018), mostrou que a diversidade dentro da empresa gera mais lucro. O estudo foi feito com base em mais de mil empresas em 12 países e apontou que ter mulheres em cargos de liderança aumenta em $21 \%$ as chances de uma empresa ter desempenho financeiro acima da média.

Atualmente existe muitos estudos acerca do tema empreendedorismo, o processo de empreender, do individuo empreendedor e as caracteristicas empreendedoras, mas somente há poucos anos que a variavel gênero foi incluida nas pesquisas e estudos mais especificos quanto a empreendedorismo feminino no mundo. Apesar da inclusão dessa variavel, muitos estudos possuem uma predominancia masculina em suas amostras. Principalmente os que deram origem as principais teorias e conclusões sobre esse tema. 
Por esse motivo se faz necessário rever alguns fatores de caracteristicas, motivações e circustancias que levam ao empreendedorismo, uma vez que o resultado pode variar de acordo com o gênero.

Já existem estudos especificos para empreendedorismo feminino os quais demonstram resultados diferentres de acordo com as circunstancias sociais e pessoais, trazendo suas dificuldades e motivações (MINNITI, 2010; SARRI \&TRIHOPOULOU, 2005).

Com isso, faz-se pertinente estudar o empreendedorismo feminino. Esse estudo vai direcionar o caso brasileiro e a variável pandemia pela Covid-19 que impactou toda economia, em escala mundial. Verificando possíveis influências e características culturais e regionais que o estudo pode encontar. E por ser um tema, considerado pouco investigado, essa pesquisa busca contribuir para melhor compreenção desse assunto no contexto brasileiro.

Assim, o objetivo central desta investigação é identificar motivos e circunstâncias que levam as mulheres brasileiras a criarem os seus próprios negócios e compreender quais os obstáculos que enfrentam nessa trajetoria e as adaptações enfrentadas para se manter nessa atual crise.

O presente trabalho será dividido em duas partes: no enquadramento das especificações temáticas do empreendedorismo feminino, relacionadas aos aspectos das suas motivações e principais dificuldades; na definição e descrição da metodologia utilizada na pesquisa, apresentação dos resultados e conclusão dos mesmos.

Trazendo a importancia de verificar os fatores que contribuiram para o crescimento no empreendedorimo feminino e suas motivações e, por outro lado, por ser considerada baixa a participação feminina em relação à masculina, questiona: quais são as maiores dificuldades encontradas por mulheres para empreender, na realidade do Rio de Janeiro - Brasil, e suas especificidades?

\subsubsection{Pandemia Global}

Os primeiros casos detectados da infecção foram na China, em dezembro de 2019, inicialmente se achou que e tratava de uma pneumonia grave de etmologia desconhecida. Após alguns exames e testes, em amostras respiratorias dos doentes, foi encontrado o coronavíris (SARS-CoV-2) e pode-se constatar como o agente causador da doença COVID-19. Logo foram aparecendo outros casos em diferentes países, demosntrando uma propagação muito rápida a nível mundial, levando a Organização Mundial da Saúde (OMS) declarar, em 11 de 
março de 2020, a infecção COVID-19 como uma pandemia mundial. ( ESTEVÃO, 2020)

A transmissão ocorre por inalação ou contato direto com gotículos infectadas do nariz ou da boca, que se espalham através da respiração ou tosse que acaba contaminando não só diretamente as pessoas, como também objetos próximos da pessoa, muitas vezes de uso coletivo como mesas, cadeiras, maçanetas e outros. Como o período de incubação pode variar de 2 a 14 dias, e alguns infectados podem ser assintomaticos e transmitir o vírus, foram adotadas medidas de restrição de contato físico em vários países do mundo. (BVSMS 2021)

Em meados de março, o Brasil adota medidas de restrições mais rígidas, declarando uma quarentena, inicialmente de 15 dias, suspendendo atividades e eventos públicos, aulas da rede pública e privada, restrigiu o funcionamento de estabelecimentos e sua ocupação, recomendando o isolamento social e evitar lugares fechados que podem faciliar a propagação do vírus.

Com a propagação crescente do vírus as medidas restritivas e isolamento social se prolongaram por meses, algumas medidas e práticas foram adotadas para reduzir o contagio do vírus, como o uso de máscaras cobrindo a boca e nariz de um material que iniba ou diminua essas goticulas no ar, utilização de alcool $70^{\circ}$ nas mãos e objetos de uso coletivo, incentivo de aumentar a higienização das mãos entre outros hábitos. Aos poucos algumas restrições foram flexibilizas e adequações foram feitas no comércio, o aumento nos cuidados com limpeza e higienização passaram a ser essenciais e com maior transparência ao público. Muitas empresas não sobreviveram a crise econômica causada pela pandemia e as que resistiram tiveram que mudar o modo que trabalhava e se adaptar à nova realidade (SANAR, 2021). Nesse contexto hove um aumento dos índices de desempregados levando muitos a iniciativa de empreender algum serviço ou produto.

\subsection{Objetivo do Estudo}

O presente trabalho tem como objetivo observar e destacar as motivações, as características, os desafios e adaptações que levam as mulheres da cidade do Rio de Janeiro a criarem os seus próprios negócios. Bem como, observar se, dentro do atual cenário, foram necessárias incluir adaptações para a manutenção do empreendimento nesse período pandêmico. 


\subsection{Objetivos específicos}

Abaixo estão listadas as etapas que serão abordadas para se alcançar o objetivo do estudo. São elas:

- Compreender as diferentes visões dos autores em relação ao empreendedorismo;

- Conhecer o perfil das mulheres empreendedoras;

- Compreender os principais componentes que impactam na criação dos seus negócios;

- Identificar quais fatores e variáveis colaboram para as mulheres na criação do seu negócio;

- Destacar as adaptações realizadas para se manter no mercado.

\subsection{Justificativa e relevância do estudo}

A participação feminina, apesar de esta crescendo, ainda é considerada baixa na abertura de novos negócios. De adordo com a pesquisa GEM 2019 o nível de empreendedoras em estágio inicial cresceu $10 \%$ da população adulta feminina, em 21 das 50 economias participantes da pesquisa. Na região da América Latina e Caribe obteve as cincos maiores taxas de empreendimento inicial, no qual o Brasil ficou em terceiro lugar.

Em uma pespectiva global, o relatório sobre empreendedorismo feminino do GEM 2018/2019, pontua que as intenções empreendedoras das mulheres, de modo geral, são menores nos países de maior renda, isso se deve, em parte, porque elas possuem maiores oportunidades de emprego formal. (GEM, 2019)

Como a ação empreendedora esta diretamente ligada a fatores motivacionais, seja por oportunidade ou necessidade, e as razãos tanto motivacionais quanto os fatores de dificuldades podem variar por gênero e cultura. Estudos mais aprofundados e constantes se fazem necessários.

Desse modo o estudo em questão teve o objetivo verificar os fatores motivacionais e dificuladades encontradas na região da cidade do Rio de Janeiro por mulheres que decidiram empreender. Com o cenário atual pandémico, foi incluido no estudo as principais dificuldades e adaptações realizadas para a manutenção do negócio. 


\section{Referencial Teórico}

Neste capítulo serão apresentados e discutidos aspectos conceituais e estudos relacionados ao empreendedorismo no mundo e no Brasil assim como as abordagens de autores distintos e suas teorias em relação a esses assuntos que serão utilizados como base na análise da pesquisa deste trabalho.

\subsection{Empreendedorismo}

O Comportamento Organizacional "é uma ferramenta humana para o benefício do homem. Ele se aplica amplamente ao comportamento das pessoas em todos os tipos de organizações, tais como negócios, governo, escolas e organizações de serviços" (DAVIS e NEWSTROM, 1992, p. 5).

O tema empreendedorismo vem sendo muito pesquisado nos últimos anos, tanto a atitude empreendedora quanto o ensino empreendedor.

Alguns autores abordam o tema voltado para o ensino empreendedor e suas metodologias na educação superior e outros, há ênfase que o aprendizado decorre pela vida toda, cabendo à universidade apenas um papel de contribuição para o desenvolvimento de algumas competências (KARATKO e POLITISAPUT RIBEIRO e PLONSKI, 2019).

Nos últimos anos, esse conceito, vem despertando o interesse de muitos estudiosos da área de gestão (CORNELIUS et al, 2006). Alguns desses autores, através de pesquisas e investigações, verificaram uma mudança no nível estrutural dos negócios. Muito se devem essas mudanças a algumas situações negativas, como crises e recessões econômicas, e situações positivas, como avanços na tecnologia e globalização, o que acaba impulsionano mais o empreendedorismo e a inovação.

A Sociedade Portuguesa de Inovação (2005) diz que o empreendedorismo é apresentado como uma via central para o desenvolvimento económico, associado a um processo de criação de novos negócios, criação de novos empregos, promoção e consequente desenvolvimento da competitividade de um país.

Após a revolução industrial e o surgimento de grandes potências, como os EUA, as discussões e estudos sobre o conceito de empreendedorismo foram intensificados, podendo ser divididos em três períodos. Primeiro período, de 1986 a 1990, no qual foram 299 artigos publicados; segundo período, de 1993 a 1997, 
foram publicados 1.082 artigos sobre empreendedorismo, um aumento significativo; terceiro período, de 2000 a 2004, mostrando uma evolução crescente no interesse desse tema, foram publicados 1.785 artigos. (CORNELIUS et al, 2006).

No Brasil também observado um crescimento nos estudos desse assunto, empreendedorismo feminino. Observando uma busca mais recente, em três bases de dados (SPELL, SCIELO.BR e GOOGLE Acadêmico), foram encontrados mais de 1.000 textos publicados em cerca de 307 periódiocos brasileiros, só no ano de 2016. (REGEPE, 2016, p. 40-74)

Visto o crescente interesse dos estudiosos e politicos, em todo mundo, no conceito empreendedorismo e nos impactos na economia local e social. Buscouse formas de acompanhar e analisar o que é considerado o fenomeno empreendedorismo, a relação e impactos nas economias e desenvolmento social, assim como as dinamicas e estimulos envolvidos para empreender de cada país parcicipante (SPI, 2011), foi criado em 1999 o Project GEM (Global Entrepreneurship Monitor), uma iniciativa dos Estados Unidos, com Babson College, junto com o Reino Unido, London Business School. Sendo o primeiro estudo realizado, em larga escala e com países em parcerias sobre esse tema, e desde então vem sendo repetido a cada ano e com adesão de outros países na pesquisa.

Este relatório traz algumas analises relacionadas ao empreendedorismo, como caracteristicas, idade (entre 18 e 64 anos) e, recentemente, o gênero. Também se verifica a Taxa de Empeendedorismo Total (TTE), incluindo individuos que participam do nascimento de um negócio ou que estão a frente dele, Taxa de Empreendedorismo Inicial (TEA, do inglês,Total Early - Stage Entrepreneurial Activity) e a Taxa de Empreendedorismo Estabelecido (TEE).

Nele é considerado empreendedor emergente todo individuo que, nos últimos doze meses, manisfestou vontade ou iniciou um negócio novo, sendo dono total ou parcial dele. E que não teve remuneração, de qualquer tipo, para qualquer pessoa, dono ou sócio, por mais de três meses.

\subsubsection{Empreendedorismo no Brasil e no Rio de Janeiro}

No Brasil, desde sua inclusão na pesquisa GEM, que nos possibilita acompanhar as suas taxas de empreendedorismo, inicial (TEA) e estabelecidos 
(TEE), é possível fazer um histórico no qual podemos analisar e comparar com índices de outros países (GEM, 2019). Destacando o crescimento nos empreendimentos inicial dos últimos anos e ocupando a $4^{a}$ posição entre as economias participantes do GEM-2019. Refletindo um otimismo na economia local nesse período.

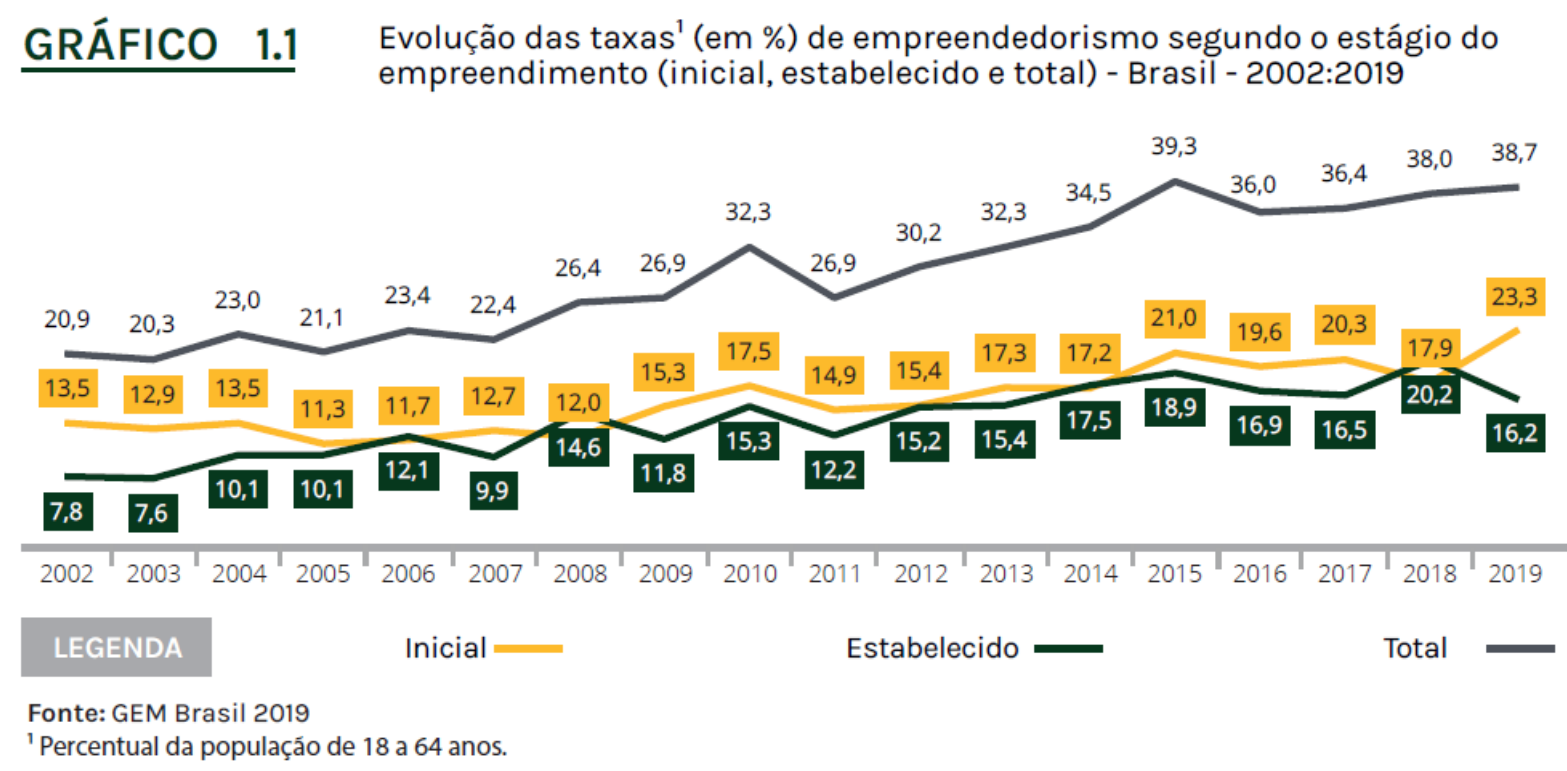

Figura 1: Evolução das taxas em \% 2002- 2019

Fonte: GEM Brasil 2019

Apesar do otimismo dos especialistas em 2019, o surgimento e a propagação da COVID-19 em 2020 causou uma enorme crise econômica mundial. Com as medidas de restrição e algumas empresas fechando ou reduzindo o tempo de trabalho houve um aumento na taxa de desemprego no Brasil ficando acima dos 14\%, uma das maiores taxas registradas pelo IBGE. (IBGE, 2021).

No comparatico de 2020 com o ano de 2019, a taxa de empreendedorismo total no Brasil caiu (-) $20 \%$, dentro do grupo de empreendimentos estabelecidos. E nos que contribuiam para geração de emprego, o índice foi ainda mais impactante, sendo de (-) $46 \%$. A falta de trabalho contribui para criação de novos empreendimentos e pequenos negócios, mas o crescimento nessa categoria foi bem abaixo do que costuma ser (imagem-2). Outro impacto da pandemia na economia é a escassez de insumos, aumentando os custos de produção o que impacta diretamente nos preços do mercado e nos novos empreendedores. 


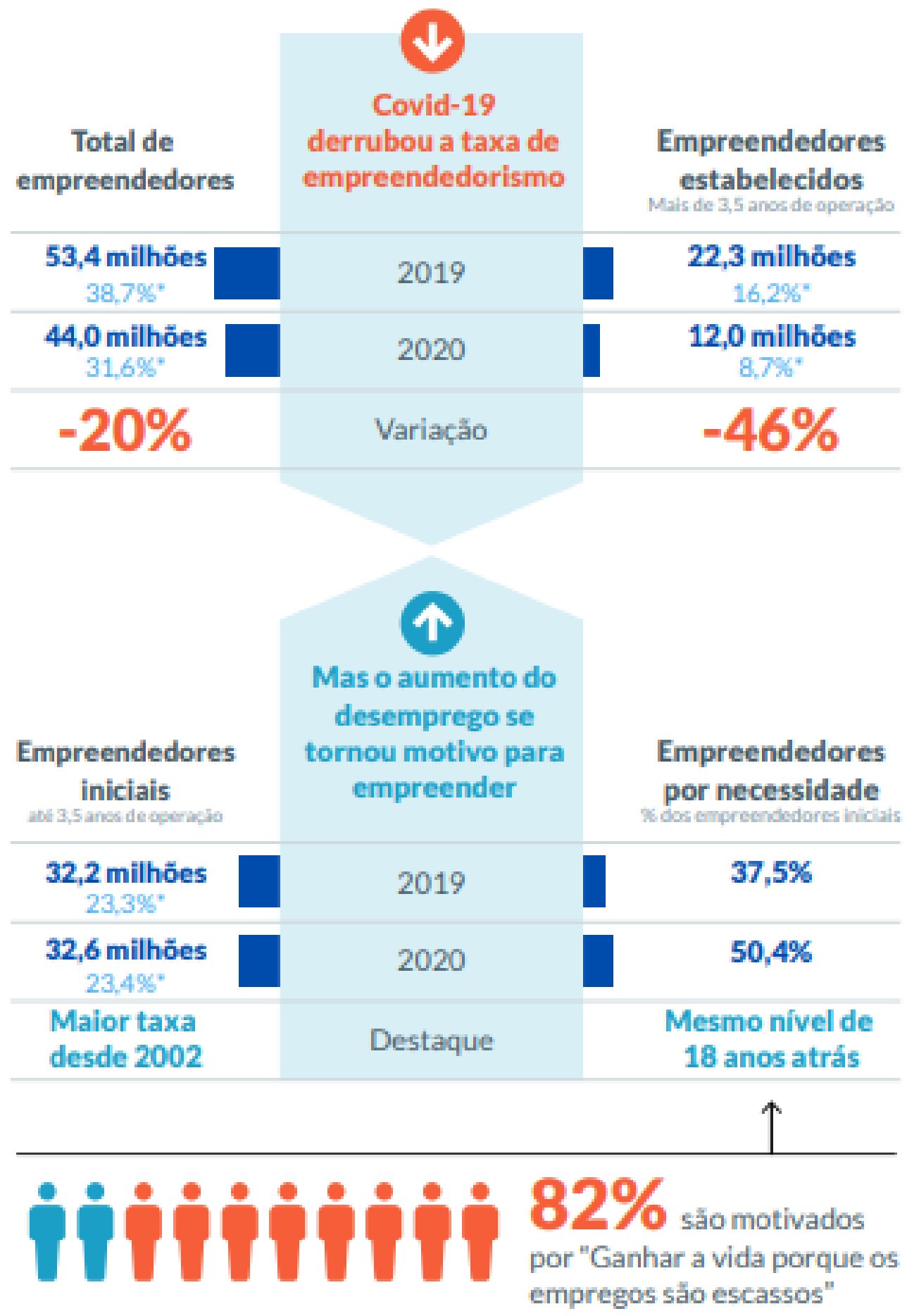

Figura.2: Taxa de Empreendeorismo \%

Fonte: GEM-SEBRAE (2020)

As micro e pequenas empresas (MPEs) tem uma grande participação na economia dos países e centros urbanos. No Rio de Janeiro essa participação chega a $90 \%$ das empresas formais, e $62 \%$ são classificados 
como Micro Empreendedor Individual (MEI). Alguns governos e agências de desenvolvimentos consideram esse segmento um pilar fundamental para o desenvolvimento da economia e alívio da pobreza, que além de fudamentar a economia e comércio gera empregos e promove a diversidade, por não necessitar de maior escolaridade e não possui tantas descriminações estruturais no mercado de trabalho, como raciais, religiosas ou por gênero. (RIOMAIS, 2021)

O Rio de Janeiro vem sendo destaque no empreendedorismo com vários polos de inovação e sedes em startups, um modelo de negócio que esta crescendo no mundo, no Brasil já são mais de 6.471 startups estruturadas e 9,7\% no Estado do Rio de Janeiro, de acordo com ABStartups (Associação Brasileira de Startups-2019). Tendo a tecnologia como ferramente principal desse segmento, facilitando a criação de ferramentas e aplicativos que facilitam ou complementam o mercado tradicional e consegue chegar a diferentes lugares através da internet. (reportagem JORNAL DO BRASIL, 2019) .

O Estado do Rio de Janeiro possui a segunda maior concentração de MEI do Brasil, um pouco mais que 1,3 milhão de microempreendedores individuais. A atual crise impactou empresas tradicionais e aumentou o número de novos empreendedores e o aumento da utilização da tecnologia, novos serviços e aplicativos. As atividades que mais cresceram são as ligadas a serviços, estética e comércio e a participação entre gêneros é praticamente igualitária, sendo 50,2\% de homens e 49,8\% de mulheres. (DATASEBRAE, 2021).

\subsection{Empreendedorismo Feminino}

Desde o início da participação feminina no mercado de trabalho, a mulher enfrenta descriminação de gênero, é subestimada em algumas funções, sofre preconceitos e pouca valorização do mercado formal, resultando em um crescimento profissional e financeiro lento. Principalmente em profissões consideradas masculinas, salientam-se a diferença salarial e um esforço maior nas atividades e na sua qualificação profissional. Em 2016 a sua participação era de $44 \%$ no mercado brasileiro, de acordo com a Organização Internacional de Trabalho (OIT), que estimou um crescimento econômico de até $\mathrm{R} \$ 382$ bilhões, em oito anos, se o país conseguir aumentar em $25 \%$ a inserção de mulheres no mercado de trabalho, estimativa feita em 2017. (UNISC,2020)

Com alguns desafios extras no mercado formal, poucas oportunidades em cargos de liderança e diferença salarial em relação aos homens, muitas mulheres 
acabam por optarem a empreender no seu próprio negócio. Na Pesquisa Nacional por Amostra de Domicílios Contínua (PNADC), IBGE-2018, se identificou que 9,3 milhões de negócios tem à frente deles mulheres, cerca de $34 \%$ do mercado brasileiro de MPEs. Comparando com outros 49 países que participam da pesquisa GEM-2018, o Brasil fica em sétimo lugar quando comparados novos empreendimentos pertencentes às mulheres. (SEBRAE, 2021)

Desde o início a mulher enfrenta desafios e dificuldades para entrar no mercado de trabalho, quase sempre possui uma jornada dupla, ao conciliar trabalho com cuidados com o lar e filhos; preconceitos dentro e fora do ambiente do trabalho; são subestimadas por profissionais da área de atuação e, às vezes, por familiares. Com o aumento da autoconfiança da mulher, necessidade financeira e pessoal e na busca por maior independência os empreendimentos femininos vem crescendo muito, atualmente a sua participação na abertura de novas MEPs chega a quase $50 \%$. Figura 3

\section{No Rio de Janeiro, 50,2\% do MEl é do gênero masculino e 49,8\% do gênero feminino.}

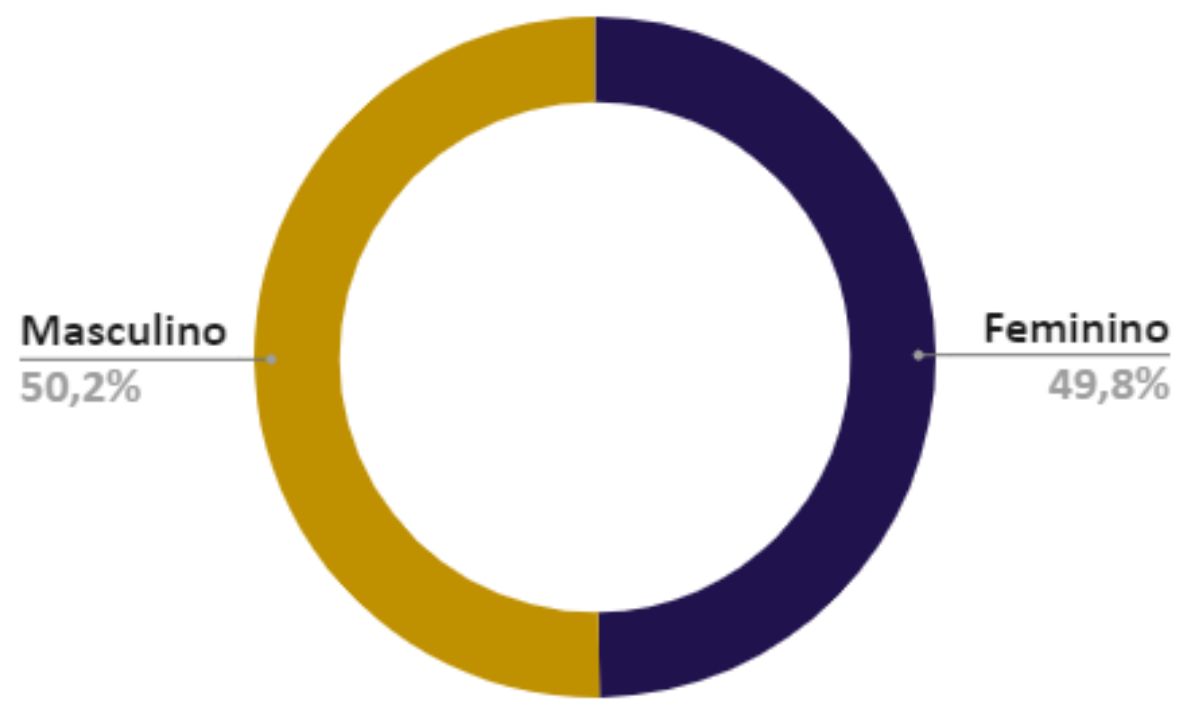

\section{Portal do Empreendedor. Dados até 23/01/2021.}

Figura 3: Perfil do empreendedor do Rio de Janeiro comparado por gênero Fonte: portal do empreendedor, SEBRAE (2021)

Apesar do crescimento na abertura de novos negócios, nesse período de pandemia, houve uma grande queda nos empreendimentos estabelecidos, que possuem mais de três anos e meio, principalmente nos geridos por mulheres com uma redução de $62 \%$ comparados com o ano de 2019 , para os homens a redução 
foi de $35 \%$ nesse mesmo período. A análise faz parte do relatório anual “Empreendedorismo no Brasil 2020" do Global Entrepreneurship Monitor (GEM), que contou com apoio do Serviço Brasileiro de Apoio às Micro e Pequenas Empresas (Sebrae) e do Instituto Brasileiro de Qualidade e Produtividade (IBPQ). (EMPREENDER360, 2021).

\subsection{Motivação}

A motivação, de maneira resumida, é um conceito que explica impulsos comportamentais que um indivíduo pode ter perante a uma situação. No dicionário (DICIONÁRIO ONLINE, 2009-2021) seu significado esta: "Ato ou efeito de motivar, de despertar o interesse por algo. " O ser humano, diferente dos outros animais, possui raciocínio lógico e emocional, capacidade de refletir sobre seus atos, do passado ao presente e futuro, e imaginação para criação de algo novo. Ao longo de sua evolução humana a motivação foi evoluindo junto, da ação para sua sobrevivência e adaptação no meio para suprir outras necessidades intrínsecas.

Dentro do campo dos negócios foram surgindo teorias a cerca desse tema, Frederick Taylor (1856-1915) com a Escola de Administração Científica, iniciou os estudos sobre conciliar a motivação do indivíduo com a da organização, através do aumento de produtividade e remuneração. Outras teorias foram surgindo em seguida, no qual se pode constatar que as motivações vão aumentando ou mudando, de acordo com o cenário, necessidades e pessoa. (TAYLOR, F. 1911)

\subsubsection{Teorias da Motivação}

Para uma melhor compreensão da motivação para empreender, foram selecionadas algumas Teorias da Motivação, as quais vamos destacar as principais características principais. É importante observar que na visão de Bergamini, "as diferentes Teorias da Motivação não se anulam umas às outras, pelo contrário, se complementam" (BERGANIMI, 1997, apud FERREIRA et al., 2011, p. 33).

\section{Teoria X e Teoria Y de McGregor}

Para Douglas McGregor, cada administrador possui uma concepção própria a respeito da natureza humana, chegando à conclusão que existe duas 
maneiras antagônicas de moldar os comportamentos dos seus subordinados. Uma ele considerou velha e negativa, Teoria $X$, e a outra moderna e positiva, Teoria Y. Cabendo ao administrador escolher a que mais se adequa ao padrão de comportamento do trabalhador e utilizá-la.

$\mathrm{Na}$ teoria $\mathrm{X}$, acredita-se que as pessoas preferem ser dirigidas $\mathrm{e}$ comandadas, evitam responsabilidades, são sem ambição, são preguiçosas, limitadas e não gostam de mudanças. E por isso são pouco confiáveis. Nesse cenário, naturalmente, existe falta de interesse, estimulo e pouca produtividade. A motivação vem através de estímulos da punição e prémio.

Na teoria $\mathrm{Y}$, o trabalho já é visto como natural e com maior interesse e participação do trabalhador, com maior autonomia e responsabilidade, possuem objetivos comuns com a organização e são adeptos às mudanças. Tornando um ambiente mais colaborativo, com iniciativa e satisfação no trabalho. A motivação vem da união do grupo em torno dos objetivos em comum e no aumento da produtividade.

\section{TEORIA X $\mathrm{Y}$ Y de DOUGLAS Mc GREGOR}

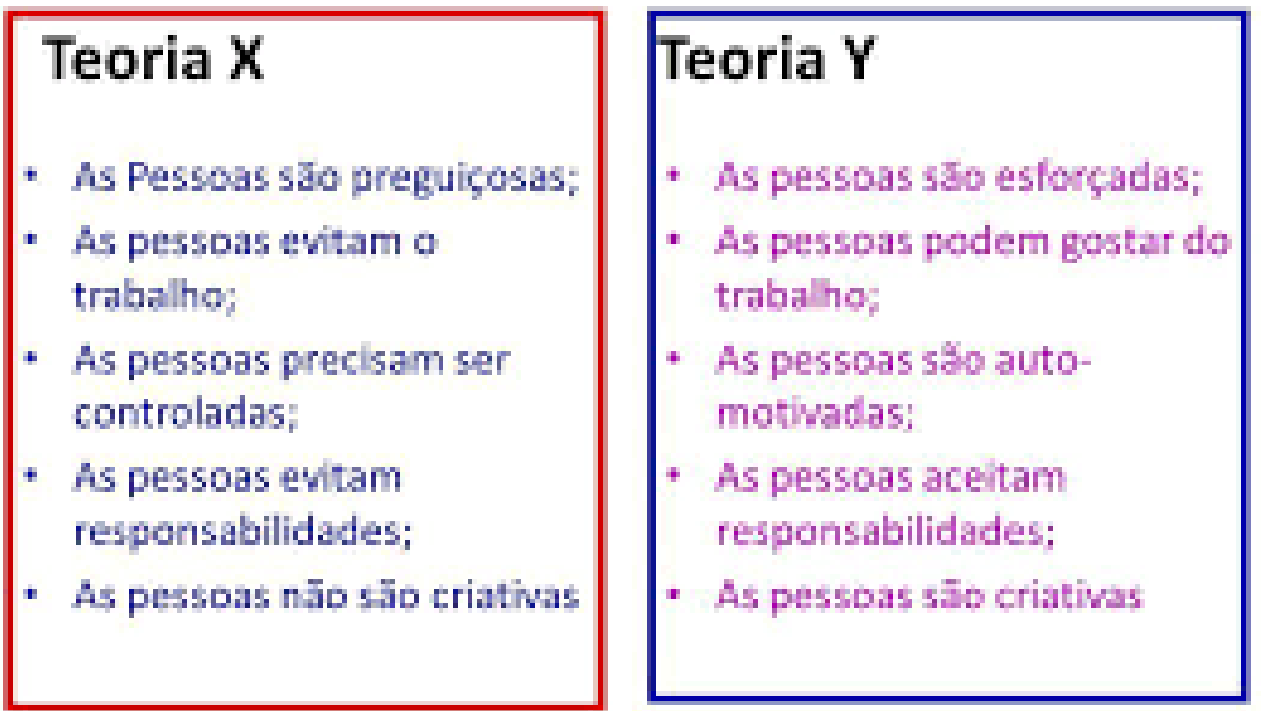

Figura 4: Comparação entre a Teoria $X$ e Teoria $Y$

Fonte: Gil (2001, p.16) 


\section{Teoria da Hierarquia das Necessidades - Maslow}

Essa teoria aborda as necessidades humanas, segundo Maslow, na qual o autor apresenta uma hierarquia das necessidades, divididas em cinco níveis ascendentes, destacando que à medida que uma necessidade é satisfeita, automaticamente, o indivíduo passa a se dedicar à próxima necessidade mais elevada, bem como se a inferior for afetada de alguma maneira, ele retorna ao ciclo para satisfazê-la.

Essas necessidades são:

- Necessidades Fisiológicas: são as básicas de sobrevivência biológica, como fome, sede, sono e moradia.

- Necessidades de Segurança: se refere a proteção e segurança do que já foi suprido anteriormente, de qualquer ameaça ou perigo físico e emocional e assegurando uma estabilidade pessoal.

- Necessidades Sociais: ligada a relacionamento humano, inclui afeições dar e receber afeto, aceitação social e amizade.

- Necessidades de Estima ou Autoestima: se refere a fatores internos e como confiança em si, autorrespeito, autoconfiança na competência profissional e autonomia; e fatores externos como status, reconhecimento, prestígio e consideração dos outros.

- Necessidades de Autorrealização: pode ser considerada a mais elevada do ser humano, maximizar suas capacidades, aptidões e potenciais. Inclui a sensação de crescimento e realização pessoal. 


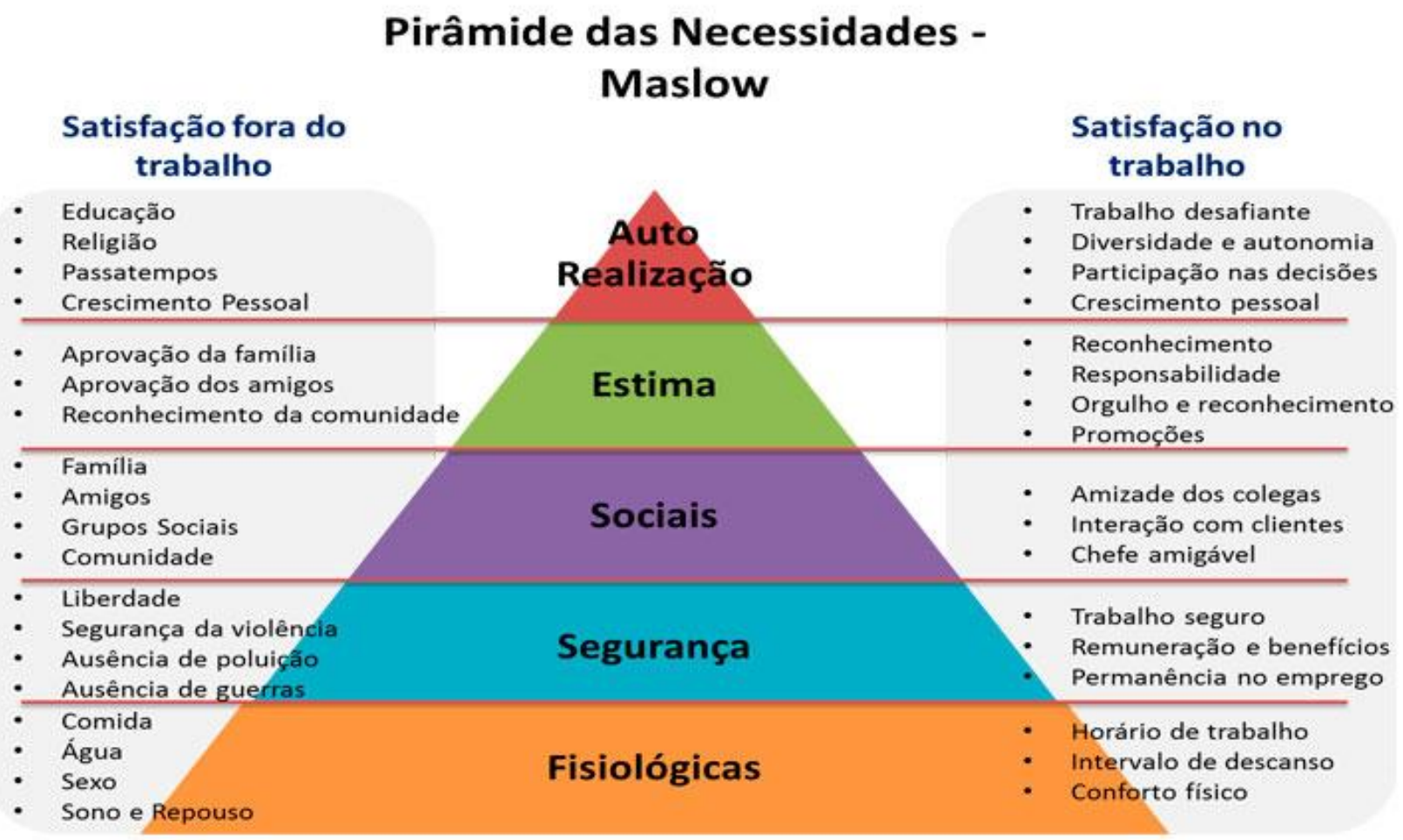

Figura 5: Hierarquia das necessidades de Maslow

Fonte: site Jovem Administrador (ANDREASI, p. 2011)

\section{Teoria dos Dois Fatores}

Também conhecida como Teoria dos fatores higiênicos e motivacionais ou Teoria da higiene-motivação, essa teoria foi proposta por Frederick Herzberg (CHIAVETNATO, 2010, P. 479) na qual traz fatores desmotivadores e motivadores para o indivíduo no trabalho.

- Fatores Higiênicos (desmotivadores): ligados ao contexto do trabalho e aos aspectos relacionados com o ambiente de trabalho. Tais como insatisfação com salário, políticas, diretrizes ou cultura da organização, segurança no local de trabalho, relação com superiores e ou colegas de trabalho.

- Fatores Motivacionais: ligados com o trabalho em si, a função excercida. A satisfação no cumprimento das tarefas, nas responsabilidades, crescimento profissional, reconhecimento e valorização dos superiores e sua realização pessoal. 
Para Herzberg, a ausência dos fatores desmotivadores provocam a insatisfação do empregado, mas sua concessão não é fator motivacional. Para se promover a motivação dos empregados os fatores higiênicos têm que estar atendidos para que os fatores motivacionais sejam alcançados.

\begin{tabular}{|c|c|}
\hline Fatores Motivacionais & Fatores Higiênicos \\
\hline Trabalho em si. & Condições de trabalho. \\
\hline Realização. & Administração da empresa. \\
\hline Reconhecimento. & Salário. \\
\hline Progresso. & Relações com o supervisor. \\
\hline Responsabilidade. & Benefícios e incentivos sociais. \\
\hline
\end{tabular}

- A satisfação no cargo depende dos fatores motivacionais.

- A insatisfação no cargo depende dos fatores higiênicos.

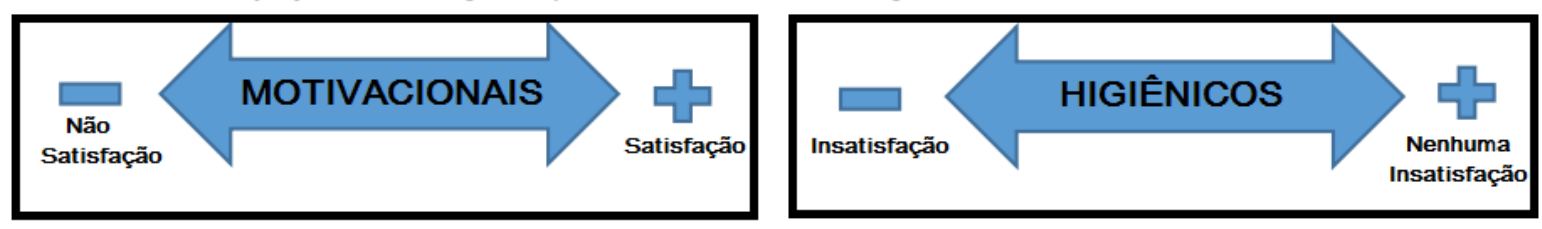

Figura 6: Fatores motivacionais $X$ higiênicos de Herzberg

Fonte: Adaptado de RIBAS \& SALIM (2016, p.128)

\section{Teoria do Estabelecimento de Objetivos}

Nessa teoria, Edwin Locke observa que a motivação do indivíduo está ligada ao cumprimento de um determinado objetivo, resultando no trabalho e esforço para atingi-lo. Neste conceito, os objetivos influenciam o comportamento das pessoas, podendo melhorar seu desempenho e gerar motivação. (LOCKE, E.A, 1984, p.241-152).

Para esses objetivos provocarem motivação, e não o efeito contrário, é necessário que sejam estabelecidos dentro de alguns critérios como:

- Ser desafiador: objetivos mais difíceis contribuem para um melhor desempenho, mas devem ser factíveis e dentro da realidade do momento ou função.

- Ser claro e mensurável: estabelecer a meta a ser realizada com especificações de quanto ou o que se quer atingir e quando ou prazo para isso. 
- Gerar comprometimento: compartilhando os objetivos e na contribuição para desenvolver o processo e as metas.

- Ser admissível: precisa fazer sentido para a pessoa e não ferir valores pessoais.

A conclusão dessa teoria é de que a criação de objetivos difíceis e específicos consegue gerar uma poderosa força motivadora, mas desde que haja envolvimento do empregado no estabelecimento de metas e que a organização propicie as condições necessárias ao atingimento das mesmas.

\subsection{Motivação no Empreendedorismo Feminino}

O empreendedorismo pode ser visto de muitas formas. Tais como: transformar o próprio sonho em realidade, conquistar independência financeira, etc.

De acordo com Custodio (2011), empreendedores são pessoas diferenciadas que possuem motivação única, são apaixonadas pelo o que fazem, querem ser o diferencial, querem ter o seu reconhecimento e serem admiradas, imitadas e referenciadas deixando o seu legado.

Se tratando de empreendedorismo feminino, essas definições são mais abrangente. Conforme Cassol (2006), com o crescimento da participação da mulher no mercado de trabalho, surge uma necessidade e o interesse acerca das suas características pessoais e comportamentais à frente dos negócios, uma delas é a motivação.

De acordo com Maximiano (2000), motivação - palavra derivada do latim motivus, movere, que significa mover - é o processo pelo qual um conjunto de razões ou motivos explica, induz, incentiva, estimula ou provoca algum tipo de ação ou comportamento humano.

Se tratando de motivação e levando em consideração as respostas das empresárias em relação a motivação que as levaram a empreender, a principal foi a realização pessoal. Além dessa, teve a flexibilidade no horário 


\section{Metodologia}

Nesta seção são apresentados os procedimentos metodológicos necessários para o alcance dos objetivos desta pesquisa.

O delineamento da pesquisa envolve várias etapas, por meio de procedimentos bem detalhados a fim de responder ao problema de pesquisa Gil (1994).

A metodologia é o estudo da organização, dos caminhos a serem percorridos, para se realizar uma pesquisa ou um estudo, ou para fazer ciência. É onde se define o modo ou método que levarão à obtenção dos dados e as técnicas que serão utilizadas para alcançar uma detalhada análise desses dados coletados a fim de obter determinado conhecimento sobre o assunto pesquisado.

Para Fonseca (2002), métodos significa organização, e logos, estudo sistemático, pesquisa, investigação.

O método da pesquisa é fundamental para se chegar aos objetivos pretendidos e através dele, é possível atestar a veracidade dos fatos e explicar de forma clara os objetos de estudos. De uma forma geral, existem dois grandes métodos de pesquisa: qualitativo e o quantitativo.

$\mathrm{Na}$ pesquisa qualitativa deve-se considerar tudo que estiver relacionado com o universo da pesquisa. A compreensão do fenômeno em estudo se dá pela análise das perspectivas das pessoas nele envolvidas, onde dados coletados são instrumento para compreensão do desempenho do fenômeno (GODOY, 1995).

Porém, quanto à abordagem, esta pesquisa classifica-se como quantitativa. Fonseca (2002, p. 20) reintera que:

\footnotetext{
"Os resultados da pesquisa quantitativa podem ser quantificados. Como as amostras geralmente são grandes e consideradas representativas da população, os resultados são tomados como se constituíssem um retrato real de toda a população alvo da pesquisa. A pesquisa quantitativa se centra na objetividade. Influenciada pelo positivismo, considera que a realidade só pode ser compreendida com base na análise de dados brutos, recolhidos com 0 auxílio de instrumentos padronizados e neutros. A pesquisa quantitativa recorre à linguagem matemática para descrever as causas de um fenômeno, as relações entre variáveis, etc. A utilização conjunta da pesquisa qualitativa e quantitativa permite recolher mais informações do que se poderia conseguir isoladamente."
}

Quanto à finalidade da pesquisa, é de classificação descritiva, serão abordadas características de uma população ou de um determinado fenômeno, 
onde serão estabelecidas correlações entre variáveis e será definido sua natureza (VERGARA, 2009).

Para fins desta pesquisa, foi realizada uma abordagem quantitativa à partir dos relatos da trajetória de vida de mulheres empreendedoras.

\subsection{Procedimentos e instrumentos de coleta de dados utilizados no} estudo

A coleta de dados foi realizada no período de novembro de $2021 \mathrm{com}$ o objetivo de analisar as características e desafios do empreendedorismo feminino através de um questionário que foi disponibilizado diretamente as entrevistadas.

Os sujeitos da pesquisa foram escolhidos por acessibilidade, ou seja, pela facilidade de acesso aos indivíduos (VERGARA, 2009). Sendo elas, mulheres empreendedoras da cidade do Rio de Janeiro.

Foi utilizado como instrumento o questionário que segundo Severino (2007, p.125) "é o conjunto de questões, sistematicamente articuladas, que se destinam a levantar informações escritas por parte dos sujeitos pesquisados, com vistas a conhecer a opinião dos mesmos sobre os assuntos em estudo".

A fim de apresentar características dos entrevistados, foram abordadas as variáveis de gênero, idade, grau de escolaridade, assim como as indagações sobre motivação, dificuldades, desafios e questões relacionadas a pandemia.

\subsection{Formas de tratamento e análise dos dados coletos para o estudo}

A análise de dados foi conduzida segundo o método de análise de conteúdo dos questionários de forma a atender aos objetivos gerais e específicos da pesquisa e exprimir assuntos relevantes para o estudo.

O questionário foi analisado qualitivamente e as respotas foram organizadas e analizadas de acordo com teorias apresentadas e dados de pesquisas secundarias com a GEM-Brasil 2019.

Não havéra apresentação dos dados pessoais através de tabela para preservar a confidencialidade das informações.

A pesquisa totalizou 15 questões que foram analisadas de forma agrupada dentro dos seus respectivos tópicos.

O referencial teórico abordado no estudo também serviu como base para 
a análise da pesquisa e para interpretar os resultados obtidos.

\subsection{Limitações do estudo}

A pesquisa teve limitações a respeito da realização da entrevista. Devido ao periodo de pandemia e para respeitar as medidas de prevensão e para evitar uma exposição ao vírus, a coleta dos dados foram através de perguntas semi estruturadas em duas etapas, uma através de um questionário com questões objetivas e com questões mais especificas e realizadas por meio digital e telefônico. Foram feitas três entrevistas com empreendedoras de diferentes sequimentos e região da cidade do Rio de Janeiro.

\section{Apresentação e análise dos resultados da pesquisa}

Após a coleta dos dados, foi feita a análise das respostas aos questionários em que se buscou verificar se os resultados observados correspondem aos resultados esperados pelas hipóteses ou questões da pesquisa.

\section{Descrição dos resultados e estrutura do questionário}

Na primeira etapa da coleta de dados, com questões objetivas foram questionados, para validação se possui ou já possuiu um empreendimento, idade, escolaridade, foram apresentadas as opções de motivações para iniciar o empreendimento iguais às do formulário GEM-Brasil 2019 e em seguidas opções formuladas de acordo com as teorias de motivação e se teve alguma dificuldade relacionadas ao gênero.

Já na segunda etapa, com questões mais objetivas foram questionados os desafios mais marcantes encontrados no início e trajetória do empreendimento, as adaptações durante o período de pandemia e foram incluídas questões sobre uso da internet como ferramenta no período de restrição e distanciamento social. 


\subsection{Análise dos resultados}

A amostra obtida para a pesquisa, apesar de pequena, se mostrou significativa pois comtenpla regiões destintas da Cidade do Rio de Janeiro e demonstrou um resultado diferente do esperado.

\section{Observações sobre as entrevistas :}

Entrevistada 1: faixa etária de 35 a 44 anos, escolaridade de nivel técnico, empreendimeto por oportunidade. Destacou como uma dificuldade inicial falta de apoio pessoal (familiar ou amigos), principal motivação inicial foi obter uma ocupação e flexibilidade de horario.Por ser tratar de uma jovem viúva e com filho adulto ela optou em assumir uma loja virtual ja estruturada e por gostar de viajar a flexibilidade de horario e possibilidade de "levar o trabalho para onde fosse" isso contribuiu para escolha do tipo de negócio.Durante a trajetória, a maior dificuldade relatada foi - "estar bem todos os dias para seguir em frente". Foi possivél perceber também que o trabalho, nesse caso, servia como uma terapia ocupacional com benefícios a saúde mental da pessoa e ajudando no tratamento de depressão. Por se tratar de um empreendimento recente e ser uma loja virtual não teve novas adaptações atribudas a pandemia, apenas alguns procedimentos e preocações de higiene na separação das encomendas.

Entrevistada 2: faixa etária de 25 a 34 anos, escolaridade de nivel superior, empreendimento por necessidade, destacou como dificuldade inicial a falta de apoio pessoal (familia ou amigos) e durante a trajetória foi - "saber como direcionar para o público correto". Sentiu pouco apoio do marido no inicio, tem duas filhas e por isso acaba tendo menos tempo do que gostaria para se dedicar ao negócio. Como principal motivação foi 'fazer a diferença no mundo' e realização pessoal, busca pequenos cursos onlines e grupos com dicas e apoio a mulheres empreendedoras - "nesses grupos tem bastante dicas de cursos, tecnas de promover seu produto e isso ajuda muito". Durante a pandemia sua principal dificuldade foi a de depender totalmente do digital, ferramentas e plataformas digitais, apesar de já utilizá-las, mas não de maneira principal. Relatou uma grande adaptação na vida pessoal e profissional, pois teve que refazer toda a sua rotina e das filhas. 
Entrevistada 3: faixa etária de 35 a 44, escolaridade de nivel superior, empreendimento por oportunidade, destacou como dificuldade inicial a timidez para se expressar ao público e sair da zona de conforto, durante a trajetoria a dificuldade foi o impacto nos estudos - " teve períodos que quase não dormia, tinha que estudar para as provas e fazer as encomendas". Como principal motivação inicial foi 'fazer a diferença no mundo' e realização pessoal, essa empreendeora dedica parte dos ganhos às causas filantropicas. $\mathrm{O}$ inicio do negócio foi para arrecar fundos para uma doação e sem intenção de longo prazo, mas foi um sucesso e o que era um projeto virou uma empresa.

Atualmente ja gera um emprego, algo de grande satisfação para a empreendedora, e consegue ser autosuficiente. Por ainda conservar conceitos filantrópicos, não busca ter lucros elevados, com frequência faz doações, seja de origem financeira ou através de seus produtos (doces) a pessoas carentes "muitas vezes encontro pessoas tristes na rua, até desesperadas, começo a conversar e dou um dos meus doces para ela e acabo mudando o seu dia".Durante a pandemia a principal dificuldade foi se adaptar da modalidade de venda presencial para a online. O contato com as pessoas era um diferencial do trabalho, fez muitas amizades e parcerias.

Nenhuma das entrevistadas relataram dificuldades relacionadas ao gênero, suas dificuldades foram relacionadas à manutenção do negócio, recursos financeiros limitados e, durante a pandemia, utilização de ferramentas digitais.

\section{Analise das questões:}

Para melhor visualização dos resultados deste tópico, apresenta-se a seguir as respostas obtidas por gráficos ou de forma descritas.

Na primeira pergunta foi somente solicitado o primeiro nome para que as entrevistadas pudessem ficar mais a vontade e contribuir para o anônimato:

\section{1- Nome :}

Nilcilene

Bruna

Samya 


\section{2- Faixa Etária :}

Duas das entrevistadas possuem idade de 35 a 44 anos e apenas uma de 25 a 34 anos. Ambas as idades estão dentro da maior concentração da idade da maioria dos empreendedores no Brasil, de acordo com a pesquisa GEM-2019 (figura 8).

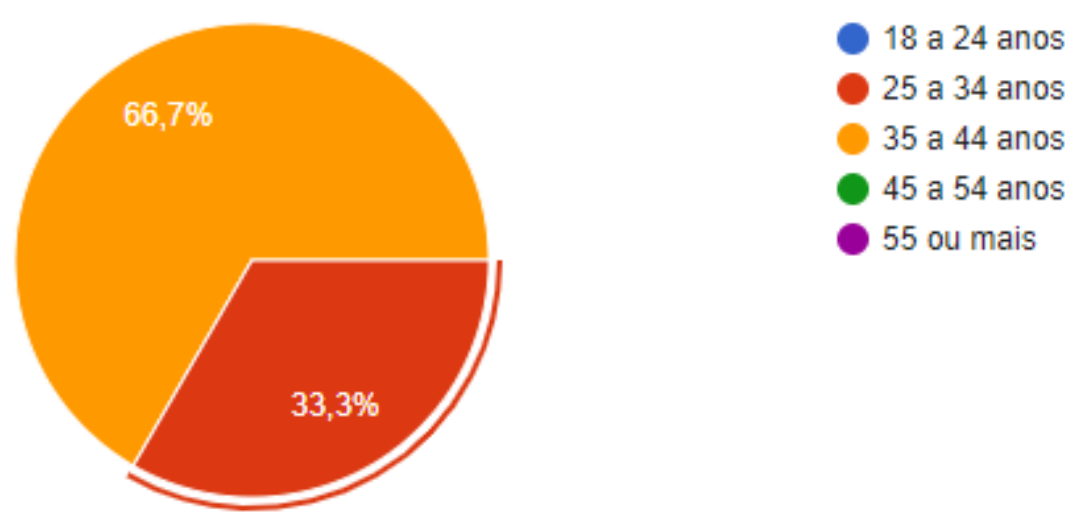

Gráfico 1: faixa etária

Fonte: autor

\begin{tabular}{|l|c|c|}
\hline Faixa etária & Iniciais & Estabelecidos \\
\hline 18 a 24 anos & 19,3 & 8,2 \\
25 a 34 anos & 27,7 & 19,4 \\
35 a 44 anos & 27,1 & 26,5 \\
45 a 54 anos & 18,2 & 27,5 \\
55 a 64 anos & 7,7 & 18,4 \\
\hline Total & 100,0 & 100,0 \\
\hline
\end{tabular}

Figura 7: faixa etária de empreendedores Total (homens e mulheres) - perfil Brasil Fonte : GEM - 2019

\section{3- Escolaridade}

Todas as entrevistadas consideram importante ter um nível de instrução para contribuir na manutenção do seu negócio e interesse na busca por mais 
informação e cursos, como os oferecidos pela SESC e Sebrae RJ. Foi possível perceber que as entrevistadas buscam ferramentas tecnológicas, como aplicativos e podcasts, para contribuir no aprendizado e como incentivo no negócio.

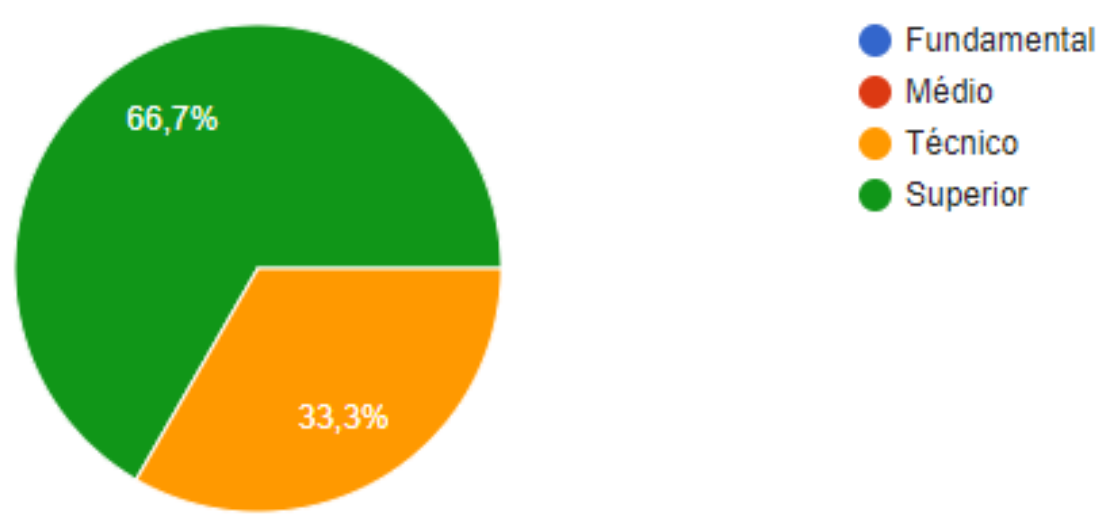

Gráfico 2: Escolaridade das entrevistadas

Fonte: autor

\section{4- Tipo de Empreendimento}

1) Comércio de prata

2) Venda de tapower pela internet

3) Venda e encomenda de doces

5- Esse empreendimento foi por oportunidade ou necessidade?

Apesar de aparecer na pesquisa GEM-2019, empreender por necessidade, na amostra a maioria das entrevistadas eram por oportunidade. 


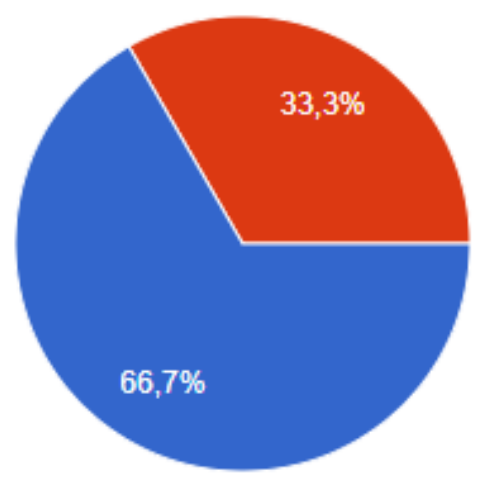

Gráfico 3: oportunidade X necessidade

Fonte: autor

6- Destaque uma dificuldade encontrada no inicio do processo de empreender, pode ser de origem particular/familiar ou profissional/burocrática:

1) "Inexperiência em gerir um negócio"

2) "Saber como direcionar para o público correto"

3) "Era muito tímida e tinha dificuldade em me expressar em público "e pouco recurso financeiro".

7- Teve algum motivo que te fez desistir do seu negócio ou querer desistir?

Para essa opção, foram colocadas opções de respostas para evitar qualquer tipo de constrangimento ou exposição da entrevistada e uma opção de outro para uma resposta diferente das descritas. Pelo gráfico, pode ser visto que uma questão bem comum enfrentada pelas empreendedoras é a falta de apoio pessoal, seja família ou amigos. 


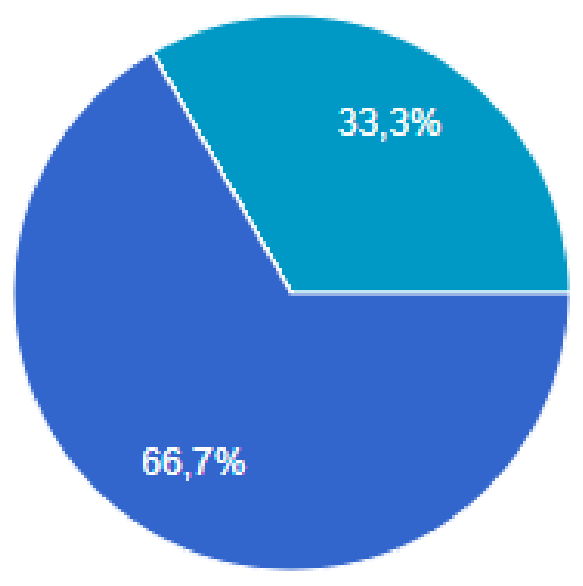

falta de apoio familiar ou amigos

dificuldades de manter o negócio

proposta para um trabalho formal

busca por um trabalho com maior estabilidade financeira

não tive motivos

atrapalhou os estudos da faculdade

Gráfico 4: Teve algum motivo que te fez desistir do seu negócio ou querer desistir Fonte: autor

\section{8- Qual dessas motivações, mas se assemelha, com o motivo que te fez empreender ? (opções retirada da pesquisa GEM Brasil)}

Essa questão foi inserida para ser utilizada em comparativo com a seguinte, que coloca opções de motivação de iniciar um negócio um pouco diferente da pesquisa GEM - 2019.
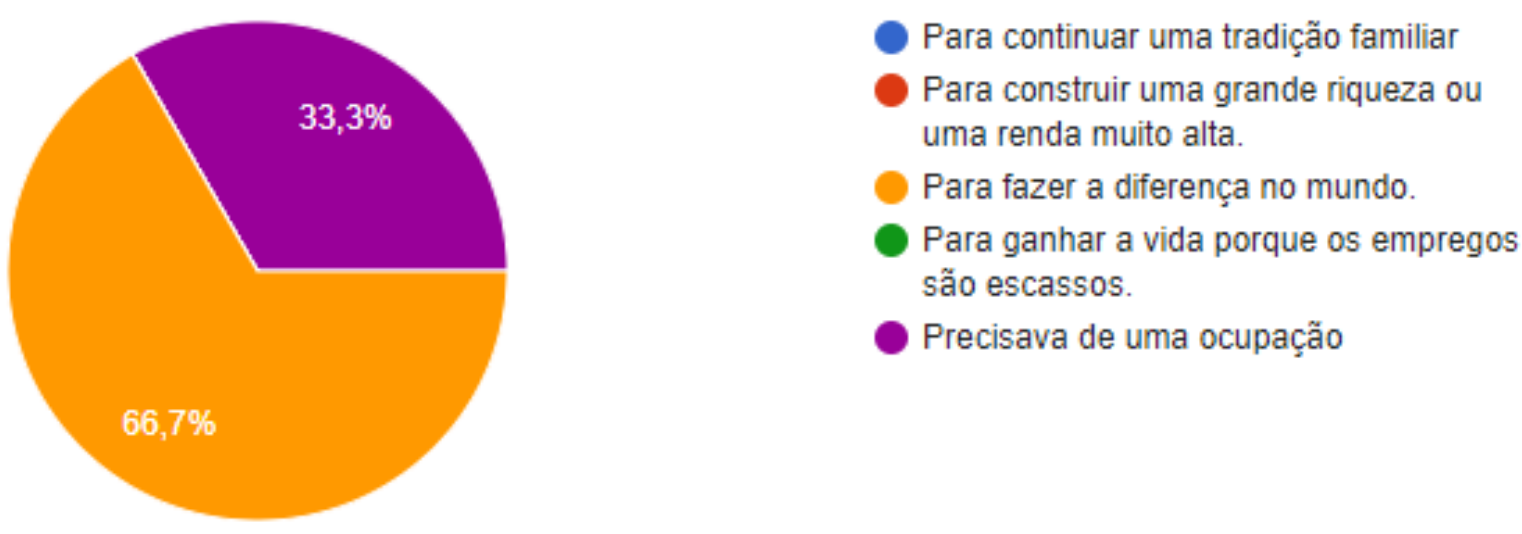
uma renda muito alta.

Para fazer a diferença no mundo.

- Para ganhar a vida porque os empregos são escassos.

Precisava de uma ocupação

Gráfico 5: motivações utilizando opções retirada da pesquisa GEM Brasil)

Fonte: autor 
9- Qual dessas motivações mais se enquadra com a razão de iniciar um empreendimento?

Nessa questão foram dadas opções diferentes de motivação, foi retirada a opção 'tradição familiar' e colocada a "flexibilização de horário de trabalho" e a demais opção consideramos semelhantes, apesar de terem algumas diferenças. Pode se considerar o resultado semelhante das questões.

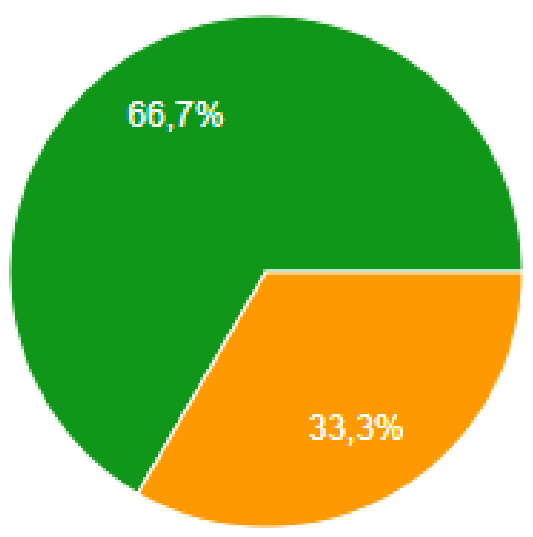

financeira, falta de um trabalho formal vontade de ter o próprio negócio

flexibilidade no horário de trabalho para conciliar com outras atividades como família, estudos ou outros.

realização pessoal

Gráfico 6: motivações

Fonte: autor

10- Durante sua trajetória no empreendimento, tem alguma dificuldade ou desafio que mais te marcou?

1) "Não, estou a pouco tempo no empreendimento". - Dificuldades relatas referente a início e manutenção do negócio

2) "Momentos em que estive desanimada com as vendas"

3) "...sair da zona de conforto".

11-Teve algum tipo de recriminação ou preconceito por ser mulher? (seja por parte de amigos/parentes ou no ambiente de trabalho) 
Todas responderam que não.

\section{2-Durante a pandemia, no seu negócio, precisou fazer muitas adaptações ou se reinventar ?}

Nessa pergunta, só teve uma resposta negativa porque o negócio em questão se iniciou após a pandemia.

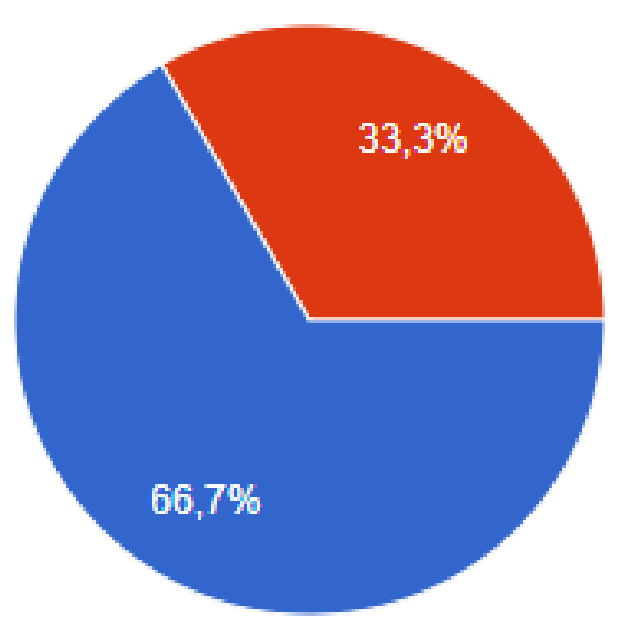

Gráfico 7: porcentagens do impacto da pandemia no negócio Fonte: autor

13-Se sim, qual a que você considera a maior mudança ou mais difícil ? Por que?

A principal dificuldade encontrada foi depender totalmente da internet e redes sociais para se manter no negócio, a maioria quase não usava os aplicativos. O mais utilizado pelas entrevistadas é o instagran.

1) "Tentar mudar a mim mesma"

2) "Se adaptar ao digital"

3) "no início, na transição da venda física para virtual" 


\section{4- Durante a pandemia cresceu muito a utilização de plataformas digitais e serviço de delivery. Isso contribui para seu negócio?}

Todas afirmaram que sim. No inicio teve uma leve registência por parte delas, mas depois se adaptaram e relatam ainda precisar de melhorias nas postagens.

\section{5-Você já utilizava esses serviços no seu negócio?}

Nessa questão podemos verificar que pouco se usava da ferramenta digital para alavancar o empreendimento da amostra. Uma relata utilizar apenas o intagran, outra já iniciou como loja digital e a terceira utiliza outros aplicativos.

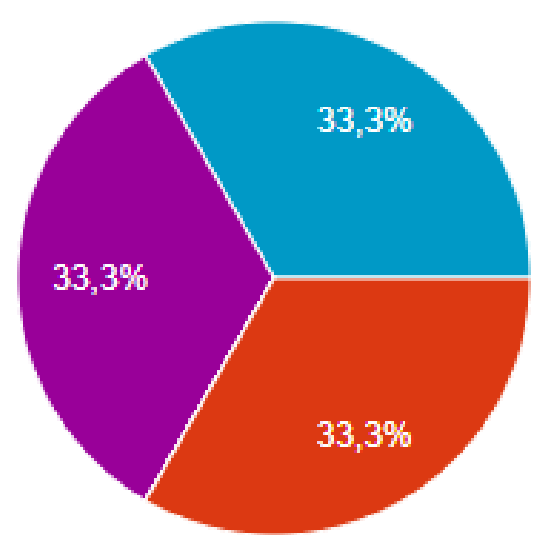

Delivery

plataformas digitais

os dois

não utilizava

instagran

Negócio recente

Gráfico 8: ferramentas digitais

Fonte: autor

\section{Conclusões, sugestões e recomendações para novos estudos}

Durante o estudo, na amostra utilizada, não foi registrada dificuladade por gênero, apesar de tratar de produtos diferentes, todas eram ligadas ao comércio direto e se trata de uma área bem homogênea. Havendo uma necessidade de investigação em outros setores e seguimentos, acredita-se que áreas predominadas pelo gênero masculino exista uma registência por gênero. 
Observando o quadro abaixo retirado da pesuisa GEM-Brasil 2019, identificamos que a motivação "porque os empregos são escassos" aparecem em $90,8 \%$ da amostra do genero feminino, uma vez que poderia escolher mais de uma opção. Na pesquisa realizada nesse trabalho foi solicitado apenas uma opção de escolha e foi inserido a opção de 'outros', caso não houvesse identificação nas respostas, e a opção dominante "empregos são escassos" não foi escolhida, mostrando não ser a principal motivação.

\begin{tabular}{l|c|c|}
\multicolumn{1}{|c|}{ Motivação } & Masculino & Feminino \\
\hline Para ganhar a vida porque os empregos são escassos & 86,0 & 90,8 \\
Para fazer diferença no mundo & 49,6 & 53,2 \\
Para construir uma grande riqueza ou uma renda muito alta & 41,9 & 31,8 \\
Para continuar uma tradição familiar & 28,8 & 24,4 \\
\hline
\end{tabular}

Fonte: GEM Brasil 2019

'Empreendedores iniciais que responderam afirmativamente cada uma das questóes. As questóes náo sáo excludentes, ou seja, o empreendedor pode ter respondido afirmativamente a mais de uma.

Figura 8: percentuais de empreendedores iniciais por gênero segundo motivação do GEM Fonte: GEM Brasil-2019.

Alguns dos resultados da coleta de dados foram diferentes do esperado, como a dificuldades por gênero, para melhor conclusão do tema seria necessária uma amostra maior e incluir segmentos variáveis do comercio. Assim aumentaria a possibilidade de um resultado mais preciso.

\subsection{Sugestões e recomendações para novos estudos}

Após a realização da coleta de dados desta pesquisa identificou-se questões a serem consideradas, tais como, a ampliação das opções de motivação para empreender para as mulheres, apesar de não ter sido a primeira opção das entrevistadas, a flexibilidade no horário de trabalho seria a segunda opção de todas, uma variável que poderia se enquadrar em todos os gêneros, uma pesquisa realizada no Brasil pela Confederação Nacional da Industria (CNI) aponta que $73 \%$ dos trabalhadores brasileiros gostariam de ter um horário mais flexível no trabalho. (PORTAL DA INDUSTRIA, 2017) E uma pesquisa realizada pela Rede Mulher Empreendedora (RME), entidade de apoio ao empreendedorismo feminino, que ouviu mais de 1.000 empreendedoras de todo Brasil, revelou que 
$50 \%$ delas tiveram como motivação para iniciar seu próprio negócio a flexibilidade do horário de trabalho. (ABF, 2018)

E importante entender um pouco das teorias da motivação para entender qual melhor se adequa ao contexto. No caso acima por exemplo, flexibilidade de horário de trabalho, com base na pirâmide das necessidades de Maslow, essa questão se relaciona diretamente a satisfação fora do ambiente de trabalho, mas pode esta tanto na etapa de 'segurança', se a pessoa precisa cuidar de filhos/parentes ou se o local onde reside limita o horário de transação no percurso, quanto na etapa de 'auto realização', que pode permitir utilizar mais tempo com família, filhos ou aprimorando conhecimentos diversos.

Sugere-se também incluir em futuras pesquisas a opção de 'outros', para a questão motivação e desafios/dificuldades, para verificar se aparece alguma variável, com amostra significativa, e a sua região ou cultura local, para verificar possiveis fatores que possam influenciar nos resultados e fazer comparativos entre Estados e regiões do Brasil. Uma vez que essa coleta de dados foi na cidade do Rio de Janeiro e se trata de um grande centro urbano e de forte comércio.

Para um estudo mais direcionado aos desafios encontrados por gênero, acredita-se que é relevante fazer destinção por segmentos e setores de trabalho e industria. Na coleta de dados desde trabalho, foi realizada no setor de comércio, por se tratar de um segmento mais homogêneo não teve muita distinção da variável gênero.

\section{Referências Bibliográficas}

BERGANIMI, 1997, apud FERREIRA et al., 2011. Motivação e sua influência no ambiente de trabalho

CASSOL, Neidi K. A Produção Científica na área de empreendedorismo feminino: análise dos estudos indexados na base de dados do Institute for Scientific Information (ISI). 2006. 136 f. Dissertação (Mestrado em Administração) Universidade Regional de Blumenau, Blumenau. 2006.

CUSTÓDIO, T. P. A importância do empreendedorismo como estratégia de negócio. 2011. Monografia (Bacharelado em Administração) - Centro Universitário Católico Salesiano Auxilium, Lins- SP, 2011. 
E. A LOCKE, E. FREDERICK, C. LEE \& P. BOBKO, "Effect of Self-Efficacy, Goals, and Task Strategies on Task Perfomace", Journal of Applied Psychology, 1984, p. 241-251.

ESTEVÃO, A.- ACTA RADIOLÓGICA PORTUGUESA, Janeiro-Abril 2020 Vol 32 กำ 5-6

FONSECA, J. J. S. Metodologia da pesquisa científica. Fortaleza: UEC, 2002.

GIL, Altônio Carlos. Métodos e técnicas de pesquisa social. 4. ed. São Paulo: Atlas, 1994.

GIL, Antonio Carlos. Gestão de pessoas: enfoque nos papéis profissionais. São Paulo: Atlas, 2001.

GODOY, A. S. A pesquisa qualitativa e sua utilização em administração de empresas. Revista de Administração de Empresas, v. 35, n. 4, p. 65-71, 1995.

GUMENEZ, F. A. P.; Ferreira, J. M.; Ramos, S. C. Empreendedorismo Feminino no Brasil: Gênese e Formação de um Campo de Pesquisa. Revista REGEPE - Revista de Empreendedorismo e Gestão de Pequenas Empresas, 2016.

GOES, R. Remuneração e Mediação de Conflitos - 2016 -UNIVERSIDADE CANDIDO MENDES AVM - FACULDADE INTEGRADA PÓS-GRADUAÇÃO LATO SENSU

<http://www.avm.edu.br/docpdf/monografias publicadas/B004399.pdf/ >- acesso em: 10 de novembro de 2021

JULIANO, M. C. Relato de uma experiência metodológica para a disciplina "Empreendedorismo" em um curso de Administração. Revista ADMpg Gestão Estratégica, v. 4, n. 1, 2011.

MAXIMIANO, A. C. A. Introdução à Administração. 5. ed. São Paulo: Atlas. 2000.

SEVERINO, Antônio Joaquim. Metodologia do Trabalho Científico. 23.ed. rev. 
e atual. São Paulo: Cortez, 2007.

Site: Biblioteca Virtual em Saúde < https://bvsms.saude.gov.br/novo-coronaviruscovid-19-informacoes-basicas/> - Acesso em: 10 de outubro de 2021

Site: SANAR Saúde - Linha do tempo do Coronavírus no Brasil <https://www.sanarmed.com/linha-do-tempo-do-coronavirus-no-brasil> - Acesso em: 10 de outubro de 2021

Site: RioMais.Org - por Juliana Oliveira, janeiro 21, 2021 - A importância das micro e pequenas empresas para a cidade do Rio de Janeiro

<https://riomais.org/a-importancia-das-micro-e-pequenas-empresas-para-cidadedo-rio-de-janeiro/ > - Acesso em: 12 de outubro de 2021

Site: Jornal do Brasil, 2019 - <https://www.jb.com.br/economia/2019/08/1014901rio-de-janeiro-e-destaque-no-empreendedorismo.html>-Acesso em: 12 de outubro de 2021

Site: Data Sebrae - MEI no Estado do Rio de Janeiro $<$ https://datasebrae.com.br/mei-no-estado-do-rio-de-janeiro/\#p1-2020> - Acesso em: 12 de outubro de 2021

Site: Agencia IBGE noticiais - < https://agenciadenoticias.ibge.gov.br/agencianoticias/2012-agencia-de-noticias/noticias/31255-desemprego-fica-em-14-6-notrimestre-ate-maio-e-atinge-14-8-milhoes-de-pessoas> - Acesso em: 17 de outubro de 2021

Site: ASN - Agencia Sebrae de Noticiais, 2021- Cai participação feminina no empreendedorismo <https://www.agenciasebrae.com.br/sites/asn/uf/NA/caiparticipacao-feminina-noempreendedorismo,eecb1729baf0a710VgnVCM100000d701210aRCRD> Acesso em: 17 de outubro de 2021

Site: RioMais org - <https://riomais.org/a-importancia-das-micro-e-pequenasempresas-para-cidade-do-rio-dejaneiro/pandemia,5b9809025dbe9710VgnVCM100000d701210aRCRD> Acesso em: 17 de outubro de 2021 
Site: _UNISC_- Mulher no Mercado de Trabalho: Atuação e Importancia, 2020 <https://ead.unisc.br/blog/mulher-mercado-trabalho > - Acesso em: 22 de outubro de 2021

Site: SEBRAE, 2021 - Empreendedorismo feminino: qual a sua importância para a sociedade? <https://www.sebrae.com.br/sites/PortalSebrae/empreendedorismofeminino/artig oempreededorismofeminino/empreendedorismo-feminino-qual-a-suaimportancia-para-a sociedade,5cef0ab8f5ad7710VgnVCM100000d701210aRCRD>Acesso em: 05 novembro de 2021

Site: Emprender 360 - Resiliência é marca do empreendedorismo em tempos de pandemia, agosto 2021 <https://empreender360.org.br/resiliencia-e-marca-doempreendedorismo-em-tempos-de-pandemia> Acesso em: 05 novembro de 2021

Site: Doutor Power - maslow $2020<$ https://powerdoctor.com.br/revengspending-no-brasil-e-na-odontologia/>Acesso em: 03 novembro de 2021

Site: Portal da Industria - Brasileiro quer mais liberdade para negociar flexibilidade no trabalho, 2017

$<$ https://noticias.portaldaindustria.com.br/noticias/trabalho/brasileiro-quer-maisliberdade-para-negociar-flexibilidade-no-trabalho/ ->Acesso em: 11 novembro de 2021

Site: ABF- Portal do Franchising - Horário flexível leva mulheres aos negócios,2018 <https://www.portaldofranchising.com.br/noticias/horario-flexivelleva-mulheres-aos-negocios/ - >Acesso em: 11 novembro de 2021

VERGARA, Sylvia Constant. Projetos e relatórios de pesquisa em administração. 11. Ed. São Paulo: Atlas, 2009

RIBAS, Andreia L.; SALIM, Cassiano R. Gestão de Pessoas para Concursos. Brasília: 4ํe․ Alumnus, 2016

TAYLOR, F. Princípios de Administração Científica - SP, 2010 


\section{Anexo 1:}

Estrutura do Questionário

1. Nome:

2. Faixa Etária:

3. Escolaridade

4. Tipo de Empreendimento

5. Esse empreendimento foi por oportunidade ou necessidade ?

6. Destaque uma dificuldade encontrada no inicio do processo de empreender, pode ser de origem particular/familiar ou profissional/burocrática:

7. Teve algum motivo que te fez desistir do seu negócio ou querer desistir ?

8. Qual dessas motivações, mas se assemelha, com o motivo que te fez empreender ? (opções retirada da pesquisa GEM Brasil)

9. Qual dessas motivações mais se enquadra com a razão de iniciar um empreendimento?

10. Durante sua trajetória no empreendimento, tem alguma dificuldade ou desafio que mais te marcou?

11. Teve algum tipo de recriminação ou preconceito por ser mulher ? (seja por parte de amigos/parentes ou no ambiente de trabalho)

12. Durante a pandemia, no seu negócio, precisou fazer muitas adaptações ou se reinventar?

13. Se sim, qual a que você considera a maior mudança ou mais difícil ? Por que?

14. Durante a pandemia cresceu muito a utilização de plataformas digitais e serviço de delivery. Isso contribui para seu negócio?

15. Você já utilizava esses serviços no seu negocio? 